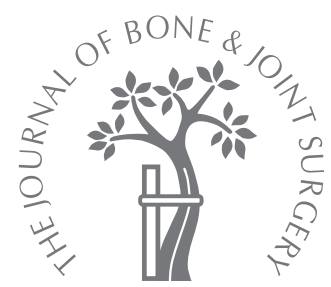

- SPINE

\title{
The presacral retroperitoneal approach for axial lumbar interbody fusion
}

\author{
A PROSPECTIVE STUDY OF CLINICAL OUTCOMES, \\ COMPLICATIONS AND FUSION RATES AT A FOLLOW-UP OF TWO \\ YEARS IN 26 PATIENTS
}

W. D. Tobler,

L. A. Ferrara

From University of Cincinnati College of Medicine, Cincinnati, United States
W. D. Tobler, MD, Associate Professor of Neurosurgery Department of Neurosurgery University of Cincinnati College of Medicine, 260 Stetson Street, Cincinnati, Ohio 45267-0515, USA.

- L. A. Ferrara, PhD, President OrthoKinetic Technologies, LLC, 2790 Creekbridge Court, Southport, North Carolina 28461, USA.

Correspondence should be sent to Dr W. D. Tobler

e-mail:

editor@mayfieldclinic.com

(C)2011 British Editorial Society of Bone and Joint Surgery doi:10.1302/0301-620X.93B7. $25188 \$ 2.00$

$J$ Bone Joint Surg $[\mathrm{Br}]$ 2011;93-B:955-60.

Received 13 May 2010

Accepted after revision 3

February 2011

The presacral retroperitoneal approach for axial lumbar interbody fusion (presacral ALIF) is not widely reported, particularly with regard to the mid-term outcome. This prospective study describes the clinical outcomes, complications and rates of fusion at a follow-up of two years for 26 patients who underwent this minimally invasive technique along with further stabilisation using pedicle screws. The fusion was single-level at the L5-S1 spinal segment in 17 patients and two-level at L4-5 and L5-S1 in the other nine. The visual analogue scale for pain and Oswestry Disability Index scores were recorded pre-operatively and during the 24-month study period. The evaluation of fusion was by thin-cut CT scans at six and 12 months, and flexion-extension plain radiographs at six, 12 and 24 months. Significant reductions in pain and disability occurred as early as three weeks postoperatively and were maintained. Fusion was achieved in 22 of 24 patients $(92 \%)$ at 12 months and in 23 patients $(96 \%)$ at 24 months. One patient $(4 \%)$ with a pseudarthrosis underwent successful revision by augmentation of the posterolateral fusion mass through a standard open midline approach.

There were no severe adverse events associated with presacral ALIF, which in this series demonstrated clinical outcomes and fusion rates comparable with those of reports of other methods of interbody fusion.

The standard open techniques of lumbar interbody fusion, which include the anterior (ALIF), posterior (PLIF) and transforaminal (TLIF) approaches, have recently been modified to become minimally invasive and renamed mini-open A-, P- and TLIF. ${ }^{1-5}$ With further refinement, TLIF may be performed through a $20 \mathrm{~mm}$ to $30 \mathrm{~mm}$ tubular retractor with skin incisions as small as $2 \mathrm{~cm} .^{5-8}$ The clinical outcomes from these approaches have been shown to be similar to or better than those reported for conventional open approaches. ${ }^{6,8-10}$ However, interbody fusion using standard A-, P- or TLIF can only be accomplished by cutting into or traumatising the supporting segmental structures, such as the anterior or posterior longitudinal ligaments, annulus, facets, lamina and muscle. Also, these approaches require partial destabilisation of the segment before it can be stabilised. ${ }^{4,9,11-13}$ Some complications are related to each particular approach. Visceral, vascular and presacral plexus injuries may be seen with ALIF, and direct injury to a nerve root and dural laceration are complications that may accompany PLIF and TLIF. ${ }^{11,12,14,15}$

An interbody fusion via a presacral retroperitoneal approach to the L5-S1 interspace and disc offers an alternative that spares the annulus and supporting tissues. ${ }^{16-19}$ Although the presacral and conventional ALIF approaches are retroperitoneal, they differ in how the retroperitoneal space is entered. The presacral space is contiguous with the fatty plane used by the conventional retroperitoneal ALIF approach. After clearance by the Food and Drug Administration (FDA) in 2004, this presacral approach was adopted for interbody fusion. ${ }^{20}$ Unlike other traditional interbody techniques, the disc is not directly exposed; rather the entire procedure is undertaken fluoroscopically. The indications for presacral ALIF are disorders that require fusion at L5-S1, such as degenerative disc disease and grades 1 or $2^{21}$ spondylolisthesis. This prospective study was designed to evaluate the safety and effectiveness of presacral ALIF over a two-year period. 


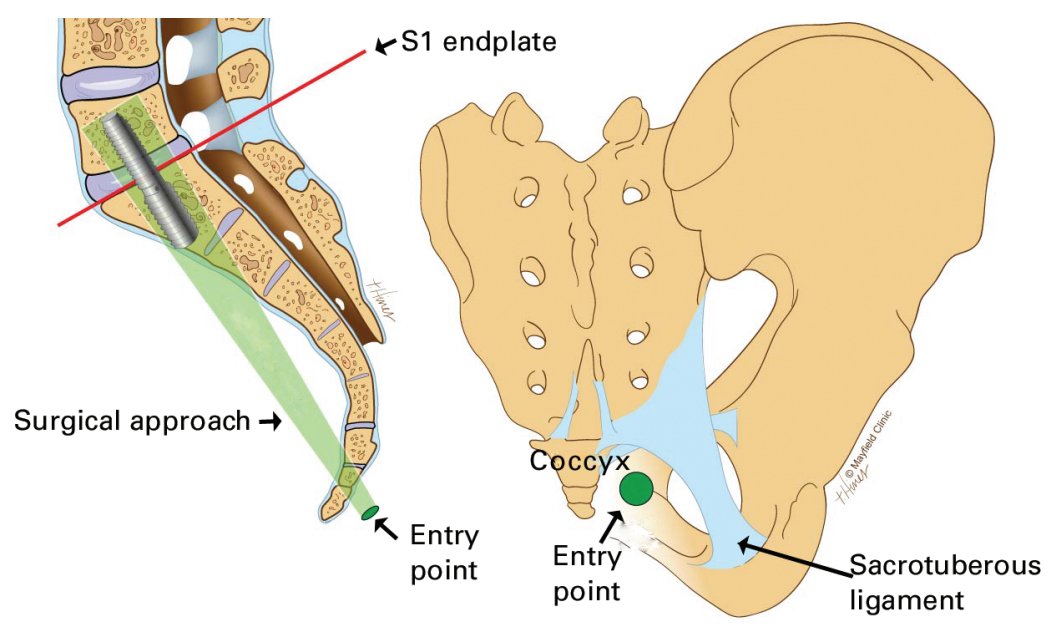

Fig. 1

Diagrams showing the surgical anatomy of the sacrum and coccyx. In order to assess the feasibility of the presacral retroperitoneal approach for axial lumbar interbody fusion, a line is drawn on the midsagittal MRI scan from the probe's entry point below the sacrococcygeal joint to the midpoint of the $\mathrm{S} 1$ endplate (red line). The implant is placed within the central shaded area (with permission from Mayfield Clinic).

\section{Patients and Methods}

In this prospective study 26 patients underwent presacral ALIF at L5-S1 with an AxiaLIF implant (TranS1 Inc., Wilmington, North Carolina) (Fig. 1) between 20 July 2005 and 26 January 2006. There were 15 men with a mean age of 44 years ( 35 to 68 ) and 11 women with a mean age of 40 years (20 to 55). The selection criteria included patients with symptomatic degenerative disc disease at L5-S1. Their mean body mass index (BMI) was 28 (21 to 36) for men and 32 (19 to 46) for women. The study was approved by our Institutional Review Board.

Of the 26 patients, 17 underwent fusion at L5-S1 alone and nine had an additional TLIF at L4-5 at the same operation. A small skin incision $(\leq 2 \mathrm{~cm})$ was placed posteriorly near the sacrococcygeal junction. Subcutaneous tissues were divided and access to the presacral space gained in a retroperitoneal manner by puncturing a single fascial layer (the anorectal fascia/ligament) located just underneath the sacrococcygeal ligament. Following discectomy and interspace bone grafting, a threaded titanium dowel was placed axially across the interspace to maintain or restore its height and provide anterior column support. The dowel, or axial rod, is manufactured in a variety of differential thread counts for either end. When inserted, the threads can distract a disc space using a reverse Herbert Screw effect. ${ }^{22}$ Distraction during the healing phase is maintained by the angulation of the rod across the space and the strength and integrity of the endplate.

Bone morphogenetic protein (BMP; Infuse; Medtronic, Minneapolis, Minnesota) and Vitoss (Orthovita, Malvern, Pennsylvania) was placed in the interbody space of 23 patients and bone marrow aspirate on a collagen sponge (Healos; DePuy Spine, Raynham, Massachusetts) in the other three. In each case, $2 \mathrm{ml}$ to $5 \mathrm{ml}$ of autograft taken from the channel created in the sacrum was implanted in the disc space. All patients also underwent simultaneous pedicle screw fixation by a minimally invasive paraspinous approach to supplement the AxiaLIF procedure.

Pre-operative MRI or CT scans and anteroposterior (AP) and lateral flexion-extension radiographs were undertaken. Post-operative imaging included CT and lateral flexionextension radiographs to assess fusion and associated features including vertebral fracture, subsidence and loosening of the implants. The extent of fusion was determined according to FDA guidance. ${ }^{19}$ The CT scans were done at the six- and 12-month follow-up and lateral flexion-extension radiographs at six, 12 and 24 months. The imaging studies were assessed by an independent radiologist (MM) using the eFILM version 2.01 software (Merge Healthcare, Milwaukee, Wisconsin). Radiolucency, subsidence or loosening of the implant, damage to the vertebrae or implant, and bone formation were recorded. Within the L5-S1 disc space, bone formation or movement at six, 12 and 24 months was assessed using our classification of fusion status (Table I), which is based on thin-section, high-resolution multiplanar CT scans. Further evaluation was conducted by a panel of reviewers, comprising the independent radiologist (MM), the principal investigator (WDT) and an orthopaedic surgeon (CS) who was a TranS1 medical advisor.

Clinical assessments were completed pre- and postoperatively, at discharge, and at three weeks and three, six, 12, and 24 months. Clinical outcomes were measured at each visit using the Oswestry Disability Index (ODI) ${ }^{23}$ and a visual analogue scale (VAS; 0 to 100) for low back pain. Statistical analysis. Demographics and clinical results are presented as descriptive statistics or frequency and 
Table I. Classification of grades of fusion at follow-up were defined on thin-section, high-resolution CT-scan reconstructions for patients who underwent axial lumbar interbody fusion (with permission from the Mayfield Clinic)

\begin{tabular}{|c|c|c|c|c|}
\hline \multirow[b]{2}{*}{ Fusion grade } & \multirow[b]{2}{*}{ Fusion description } & \multicolumn{3}{|c|}{ Number of patients (\%) } \\
\hline & & 6 months $(n=23)$ & 12 months $(n=25)$ & 24 months $(n=20)$ \\
\hline 1 & Fused: advanced bridging bone ( $>50 \%$ of available space) & $3(13)$ & $16(64)$ & $19(95)$ \\
\hline II & Fused: bridging bone $(<50 \%$ of available space) & $14(61)$ & $6(24)$ & - \\
\hline III & $\begin{array}{l}\text { Developing bone, beginning to incorporate endplates and signs of } \\
\text { bone remodelling }\end{array}$ & $4(17)$ & $2(8)$ & - \\
\hline IV & $\begin{array}{l}\text { No early evidence of bone remodelling or bridging/developing bone } \\
\text { connected to endplate }\end{array}$ & $2(9)$ & - & - \\
\hline V & $\begin{array}{l}\text { Pseudarthrosis, no bridging or developing bone, decrease or } \\
\text { non-progression; evidence of halo or loosening of screw or } \\
\text { posterior fixation }\end{array}$ & - & $1(4)$ & $1(5)$ \\
\hline
\end{tabular}

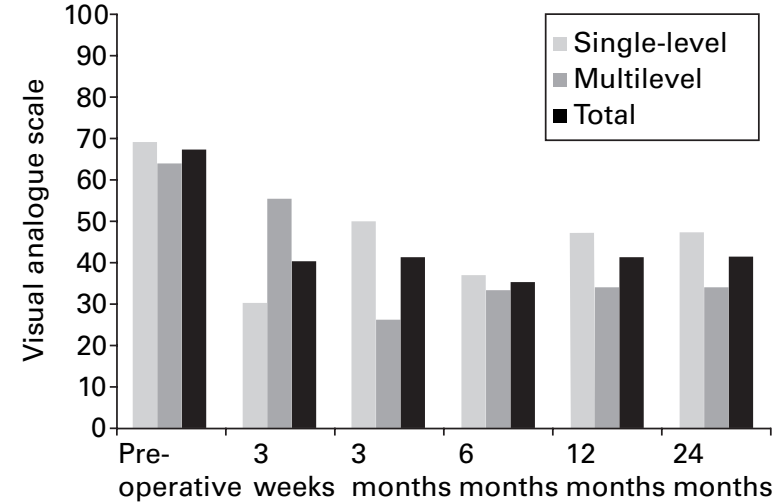

Time

Fig. 2

Bar chart showing pain levels as measured by mean visual analogue scale scores pre-operatively and throughout follow-up for patients who underwent a presacral axial lumbar interbody fusion, in relation to single- and multilevel procedures (with permission from Mayfield Clinic).

percentage distributions, as appropriate. Baseline values were compared with values at two years using a two-sided Student's $t$-test. A p-value $<0.05$ was considered to be statistically significant.

\section{Results}

The mean operative times were 191 minutes (137 to 235) for single-level fusions and 256 minutes (216 to 309) for multilevel fusions, including the time for the ancillary posterior fixation and all procedures in a multilevel operation. The mean blood loss was $137 \mathrm{ml}$ (50 to 275) in singlelevel cases and $363 \mathrm{ml}$ (50 to 600) in two-level cases. Blood loss was largely attributed to the posterior approach, with its dissection of muscle, facetectomy and decompression, all of which involve increased loss in two-level fusions. Blood loss from the presacral approach was due to back bleeding from the freshly drilled sacral channel. The mean time to discharge was slightly shorter for single-level patients than for multilevel patients ( 2.5 vs 2.7 days).

Two patients missed their six-month follow-up but returned at 12 months, and two were lost to follow-up

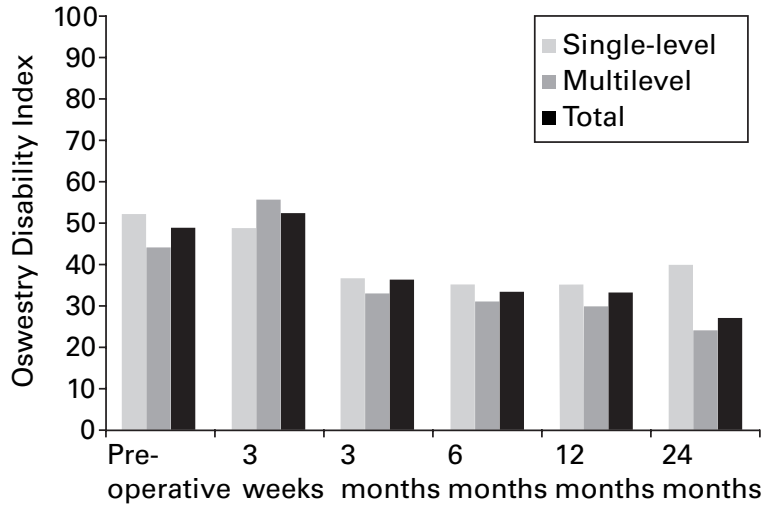

Time

Fig. 3

Bar chart showing the outcome as measured by the Oswestry Disability Index pre-operatively and throughout follow-up for patients who underwent a presacral and lumbar interbody fusion, in relation to single- and multilevel procedures (with permission from Mayfield Clinic).

during this period. At the 24-month follow-up 15 patients had lateral-flexion extension radiographs, nine did not have complete imaging studies within protocol guidelines, and 17 had complete VAS and ODI assessments. The mean VAS decreased from 67 (20 to 100) pre-operatively to 37 (10 to 80$)$ at 12 months and $37(0$ to 86$)$ at 24 months $(\mathrm{p}=0.0034$ and $\mathrm{p}=0.0070$, respectively). The mean reduction in the VAS at 12 months was 20 (0 to 40) for men and 33 (0 to 40) for women ( $\mathrm{p}=0.7225$ and $\mathrm{p}=0.1908$, respectively) (Fig. 2). At 24 months, the mean improvement was similar for both men (24 (0 to 50)) and women (26 (0 to $50)$ ). The mean VAS at three months post-operatively decreased by 35 ( 0 to 40 ) after a single-level fusion and by 10 (0 to 40$)$ after a multilevel fusion.

The mean ODI score improved from $49 \%$ (30\% to $86 \%$ ) pre-operatively to $27 \%(4 \%$ to $72 \%)$ at 24 months $(\mathrm{p}=0.0020)$ (Fig. 3). There was no statistically significant difference between men and women in respect to the 12and 24-month ODI scores $(\mathrm{p}=0.8615$ and $\mathrm{p}=0.7225$, respectively, one-way ANOVA: Neuman-Keuls comparison). The mean scores improved by $23 \%$ for women and 


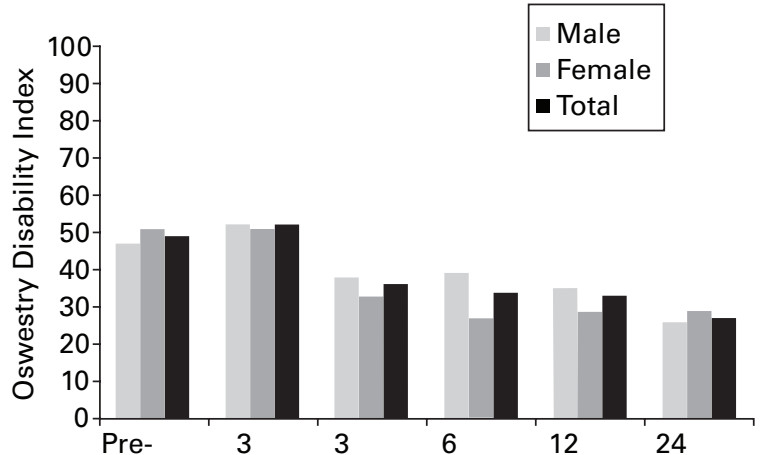

operative weeks months months months months Time

Fig. 4

Bar chart showing the outcome as measured by the Oswestry Disability Index pre-operatively and throughout follow-up for patients who underwent a presacral axial lumbar interbody fusion, in relation to the gender of the patient (with permission from Mayfield Clinic).

$20 \%$ for men at 24 months (Fig. 4). By level of involvement, the mean three-week ODI scores decreased by $2 \%$ in patients after a single-level fusion and increased by $12 \%$ in patients who had multilevel fusion.

Thus, at 24 months for single and multilevel fusions, the improvements were significant for back pain, as scores decreased by a mean of 30 in VAS and $22 \%$ in ODI scores.

On CT examination at six months, 17 (74\%) of 23 patients had fusion, three with advanced fusion grade I and 14 with grade II (Table I, Figs 5a and 5b). Another four had developing bone emanating from the endplates (grade III, Fig. 5c). Two had no evidence of bone remodelling (grade V, Fig. 5d). At the 12-month follow-up, 22 of 24 patients had fused bone (92\%), including 18 with advanced fusion grade I and four with grade II. Of the two patients who were not fused, one was developing bone that had not yet bridged (grade III, with a stable implant and a clinically significant reduction in pain and disability). The other, who had a pseudarthrosis on CT and unrelieved pre-operative pain, underwent a posterior revision which included a wide exposure and decortication of the L5 transverse processes, facets and alae of the sacrum with the addition of BMP and allograft, and with larger pedicle screws.

At 24 months, 14 of 15 patients (93\%) with appropriate radiographs were fused. Of the nine who did not have complete imaging studies three had fused on CT scans at one year and six had fused on CT between 18 and 24 months (outside the protocol study period). Thus, at 24 months, 23 patients $(96 \%)$ had fused.

No patient had any damage to the vertebral bodies at L5 or S1, such as fracture, backout, loosening or migration of the axial rod, damage to the implant or subsidence. At the six-month follow-up two patients had small areas of bone resorption and at 12 months, three had radiolucencies around the rod, one of whom had failure after a multilevel

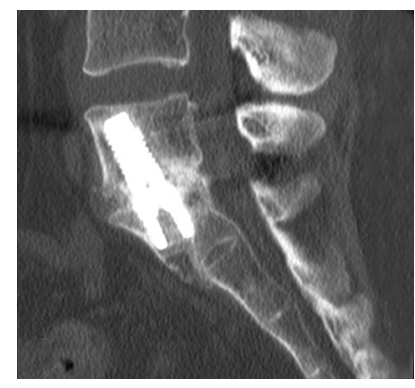

Fig. $5 a$

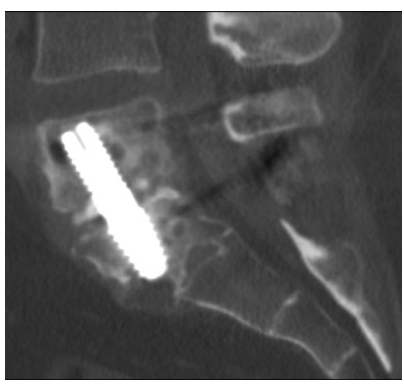

Fig. 5c

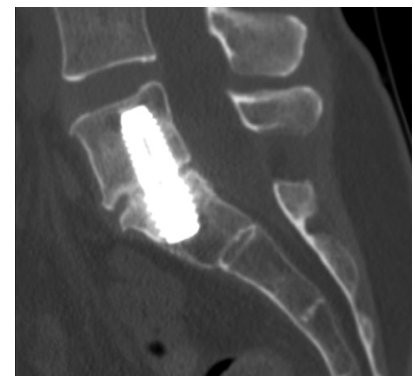

Fig. $5 b$



Fig. 5d
CT scans at one year post-operatively of different grades of fusion, showing a) grade I, continuous bridging bone extending from the L5 to the $\mathrm{S} 1$ endplate and occupying $>50 \%$ of the available space for fusion; b) grade II, bridging bone extending from the L5 to the S1 endplate and occupying $<50 \%$ of the available space for fusion; c) grade III, developing bone and bone connected to either L5 or the S1 endplate without bridging; and d) grade $\mathrm{V}$, a pseudarthrosis (with permission from the Mayfield Clinic).

fusion and underwent removal of the pedicle screws. The second had some radiolucency and focal resorption at six months, but bone was developing. He progressed to fusion at 12 months, but continued to have some radiolucency and resorption. The third patient was a 20 -year-old woman of normal weight (BMI 23). Imaging studies were not obtained at six months, but showed bridging bone at 12 months despite some radiolucency around the tip of the rod.

There were no severe complications associated with the presacral approach. Of the 34 lesser complications, ten were after single-level and 24 followed multilevel surgery. They included pedicle screw removal for pain (seven cases), painful foraminal stenosis (two) and single cases of a painful incision, nerve impingement from a pedicle screw and an unrelated rectal carcinoma requiring chemotherapy.

\section{Discussion}

Our patients who underwent presacral ALIF had a significant reduction in pain and disability, ${ }^{24}$ with rates comparable to those after conventional approaches for interbody fusion. ${ }^{1,8}$ At six months, the reductions in VAS and ODI were clearly evident, and they remained so at 24 months. Our data at 24 months are limited because protocolspecified follow-ups, namely, the flexion-extension plain radiographs, were not done for all patients, a number of whom underwent CT scanning instead. 
The rate of fusion was comparable with that in patients undergoing conventional interbody fusion, superior to allograft bone dowels, and equivalent to fusions enhanced with BMP. ${ }^{1,3,25-29}$ The blood loss was less and hospital stays shorter for our patients than for those reported after open approaches. Hospital stays after PLIF were twice as long as after presacral ALIF. 1,8,9,12,15,25,28

Obese patients usually have a larger presacral fat pad which displaces the rectum and renders the approach easier. Also, the distance from the incision to the L5-S1 disc space is fixed, regardless of weight. Therefore, unlike other approaches, the difficulties and risks of presacral ALIF are not greater with increasing obesity.

Other studies have demonstrated similar ODI outcomes after one year, ranging from $45 \%$ to $50 \%$ pre-operatively to $18 \%$ to $22 \%$ at 12 months after conventional ALIF. ${ }^{8,30}$ However, compared with ALIF, PLIF, or TLIF, the potential surgical benefits of the minimally invasive approach include minimising disruption to the surrounding tissue, allowing the structural bony margins to remain intact, lessening the risk of vascular damage and maintaining the anterior longitudinal ligament and facets to retain spinal stability, thereby reducing the risk of displacement of the implant. These benefits are effective from the outset.

In biomechanical studies, presacral ALIF has superior stability with respect to stiffness and range of movement compared to conventional ALIF and TLIF techniques. ${ }^{19,31}$ In particular, removal of the anterior and posterior longitudinal ligaments and facet joints can significantly destabilise the spine and increase movement across the spinal segment. Torsional stability in biomechanical testing for the AxiaLIF interbody device was similar to that of others, all of which play only a secondary role in reducing torsion. ${ }^{19}$ Therefore, supplementary fixation with pedicle screws is often advised with A-, T- or PLIF in which stability is worsened by distraction of ligaments and facets. Pedicle screw and/or transfacet fixation to increase torsional stability is particularly useful in the presacral ALIF approach, as it provides posterior column stability across the fusion site, and added resistance to torsion. ${ }^{32,33}$

The presacral ALIF approach may be associated with significant complications. ${ }^{17,20}$ Perforation of the rectal wall can occur if the presacral space is developed inadequately. Previous surgery in this space with resulting scarring is a contraindication to the approach. Deviation of a probe from the midline can injure the sacral nerve roots. Failure to recognise a vascular anomaly such as an aberrant iliac vein during pre-operative evaluation, or advancement of a probe above the L5-S1 disc space, can injure the iliac vessels. These complications are avoidable.

Back-out or migration of the axial rod should not occur with proper placement in patients with adequate bone density. An improper trajectory or failure to obtain highquality orthogonal fluoroscopic images increases the risks of placing it outside the vertebral body or in the spinal canal, and incomplete drilling of the sacral L5 channel or placement of the implant too far anteriorly could cause a sacral fracture. However, none of our patients developed any of these complications.

Despite observations that radiolucency and bone resorption were present, albeit diminished, at the 12-month follow-up, two patients with such findings achieved bridging bone or solid fusions. Radiolucency around any implant is a mechanical phenomenon resulting in bone deformation. The causes of bone resorption and radiolucency are related to the fixation at the site of fusion, the load-sharing environment and micromovement at the implant-bone interface, possibly due to osteolysis caused by BMP. ${ }^{34-37}$ Whereas excessive micromovement can lead to radiolucencies and nonunion, minimal micromovement can indicate the necessary stress which ultimately stimulates bone growth. Although these two terms differ by definition, they both relate to the assessment of bone integrity. However, the progression to solid fusion in two of these patients was indicative of a stable fusion site, despite the radiolucencies.

\section{Further opinion}

登 A further opinion by Professor A. Hadjipavlou is available with the electronic version of this article on our website at www.jbjs.org.uk/education/further-opinions

The authors would like to thank M. Meyers and C. Sutterlin for their assistance in the evaluation of results, and M. Kemper for providing editorial assistance with the paper.

No benefits in any form have been received or will be received from a commercial party related directly or indirectly to the subject of this article.

\section{References}

1. Burkus JK, Gornet MF, Dickman CA, Zdeblick TA. Anterior lumbar interbody fusion using rhBMP-2 with tapered interbody cages. J Spinal Disord Tech 2002;15:337-49.

2. Freeman BJ, Licina P, Mehdian SH. Posterior lumbar interbody fusion combined with instrumented postero-lateral fusion: 5 -year results in 60 patients. Eur Spine $J$ 2000;9:42-6.

3. Kuslich SD, Ulstrom CL, Griffith SL, Ahern JW, Dowdle JD. The Bagby and Kuslich method of lumbar interbody fusion: history, techniques, and 2-year follow-up results of a United States prospective, multicenter trial. Spine 1998;23:1267-78.

4. Regan JJ, Aronoff RJ, Ohnmeiss DD, Sengupta DK. Laparoscopic approach to L4-L5 interbody fusion using BAK cages: experience in the first 58 cases. Spine 1999;24:2171-4

5. Foley KT, Holly LT, Schwender JD. Minimally invasive lumbar fusion. Spine 2003;28:S26-35.

6. Isaacs RE, Podichetty VK, Santiago P, et al. Minimally invasive microendoscopyassisted transforaminal lumbar interbody fusion with instrumentation. J Neurosurg Spine 2005;3:98-105

7. Mummaneni PV, Rodts GE Jr. The mini-open transforaminal lumbar interbody fusion. Neurosurgery 2005;57:256-61.

8. Schwender JD, Holly LT, Rouben DP, Foley KT. Minimally invasive transforaminal lumbar interbody fusion (TLIF): technical feasibility and initial results. J Spinal Disord Tech 2005;18(Suppl):S1-6.

9. Regan JJ, Yuan H, McAfee PC. Laparascopic fusion of the lumbar spine: minimally invasive spine surgery: a prospective multicenter study evaluating open and laparoscopic lumbar fusion. Spine 1999;24:402-11.

10. Zdeblick TA, David SM. A prospective comparison of surgical approach for anterior L4-L5 fusion: laparoscopic versus mini anterior lumbar interbody fusion. Spine 2000;25:2682-7.

11. Regan JJ, McAfee PC, Guyer RD, Aronoff RJ. Laparoscopic fusion of the lumbar spine in a multicenter series of the first 34 consecutive patients. Surg Laparosc Endosc 1996;6:459-68.

12. Elias WJ, Simmons NE, Kaptain GJ, Chadduck JB, Whitehill R. Complications of posterior lumbar interbody fusion when using a titanium threaded cage device. $J$ Neurosurg 2000;93(Suppl 1):45-52. 
13. Modic MT, Ross JS, Masaryk TJ. Imaging of degenerative disease of the cervical spine. Clin Orthop 1989;239:109-20.

14. Lin PM. Posterior lumbar interbody fusion technique: complications and pitfalls. Clin Orthop 1985;193:90-102.

15. Scaduto AA, Gamradt SC, Yu WD, et al. Perioperative complications of threaded cylindrical lumbar interbody fusion devices: anterior versus posterior approach. J Spinal Disord Tech 2003;16:502-7.

16. Carl A, Ledet E, Oliveira C, et al. Percutaneous axial lumbar spine surgery. In: Perez-Cruet MJ, Khoo LT, Fessler RG, eds. An anatomic approach to minimally invasive spine surgery. St Louis: Quality Medical Publishing, 2006:654-70.

17. Cragg A, Carl A, Casteneda F, et al. New percutaneous access method for minimally invasive anterior lumbosacral surgery. J Spinal Disord Tech 2004;17:21-8.

18. Ledet EH, Carl AL, Cragg A. Novel lumbosacral axial fixation techniques. Expert Rev Med Devices 2006;3:327-34.

19. Ledet EH, Tymeson MP, Salerno S, Carl AL, Cragg A. Biomechanical evaluation of a novel lumbosacral axial fixation device. J Biomech Eng 2005;127:929-33.

20. Marotta N, Cosar M, Pimenta L, Khoo LT. A novel minimally invasive presacral approach and instrumentation technique for anterior L5-S1 intervertebral discectomy and fusion: technical description and case presentations. Neurosurg Focus 2006;20:E9.

21. Turner RH, Bianco AJ Jr. Spondylolysis and spondylolisthesis in children and teenagers. J Bone Joint Surg [Am] 1971;53-A:1298-306.

22. Herbert TJ, Fisher WE. Management of the fractured scaphoid using a new bone screw. J Bone Joint Surg [Br] 1984;66-B:114-23.

23. Fairbank JC, Couper J, Davies JB, O'Brien JP. The Oswestry low back pain disability questionnaire. Physiotherapy 1980;66:271-3.

24. United States Food and Drug Administration. FDA protocol G000137: a prospective, randomized clinical investigation of recombinant human bone morphogenetic protein-2 and compression resistant matrix with the CD Horizon spinal system for posterolateral lumbar fusion in patients with symptomatic degenerative disc disease: updated results. http://www.fda.gov/downloads/advisorycommittees/committeesmeetingmaterials/medicaldevices/medicaldevicesadvisorycommittee/orthopaedicandrehabilitationdevicespanel/ucm220081.pdf (date last accessed 18 May 2011).
25. Salehi SA, Tawk R, Ganju A, et al. Transforaminal lumbar interbody fusion: surgical technical and results in 24 patients. Neurosurgery 2004;54:368-74.

26. Burkus JK. Bone morphogenetic protein in anterior lumbar interbody fusion: old techniques and new technologies: invited resubmission from the Joint Section Meeting on Disorders of the Spine and Peripheral Nerves, March 2004. J Neurosurg Spine 2004;1:254-60.

27. Burkus JK, Dorchak JD, Sanders DL. Radiographic assessment of interbody fusion using recombinant human bone morphogenetic protein type 2. Spine 2003;28:372-7.

28. Burkus JK, Sandhu HS, Gornet MF. Influence of rhBMP-2 on the healing patterns associated with allograft interbody constructs in comparisons with autograft. Spine 2006:31:775-81.

29. Burkus JK, Transfeldt EE, Kitchel SH, Watkins RG, Balderston RA. Clinical and radiographic outcomes of anterior lumbar interbody fusion using recombinant human bone morphogenetic protein-2. Spine 2002;27:2396-408.

30. Glassman S, Gornet MF, Branch C, et al. MOS short form 36 and Oswestry Disability Index outcomes in lumbar fusion: a multicenter experience. Spine J 2006;6:21-6.

31. Akesen B, Wu C, Mehbod AA, Transfeldt EE. Biomechanical evaluation of paracoccygeal transsacral fixation. J Spinal Disord Tech 2008;21:39-44.

32. Kai Y, Oyama M, Morooka M. Posterior lumbar interbody fusion using local facet joint autograft and pedicle screw fixation. Spine 2004;29:41-6.

33. Madan SS, Harley JM, Boeree NR. Circumferential and posterolateral fusion for lumbar disc disease. Clin Orthop 2003;409:114-23

34. Robbins MM, Vaccaro AR, Madigan L. The use of bioabsorbable implants in spine surgery. Neurosurg Focus 2004;16:E1.

35. Schmalzried TP, Maloney WJ, Jasty M, Kwong LM, Harris WH. Autopsy studies of the bone-cement interface in well-fixed cemented total hip arthroplasties. Arthroplasty 1993;8:179-88.

36. Sandén B, Olerud C, Petrén-Mallmin M, Johansson C, Larsson S. The significance of radiolucent zones surrounding pedicle screws: definition of screw loosening in spinal instrumentation. J Bone Joint Surg [Br]2004;86-B:457-61.

37. Cunningham BW, Dawson JM, Hu N, et al. Preclinical evaluation of the Dynesys posterior spinal stabilization system: a nonhuman primate model. Spine 2010;10:775-83. 